\title{
Dysphagia, dysarthria and falls in an elderly man
}

\author{
B McGleenon, IC Steele, AP Passmore
}

A 78-year-old man was referred with a history of falls and nausea. He gave a four-week history of light-headedness made worse by standing. On two occasions, he had briefly lost consciousness and fallen to the ground without injury. A diagnosis of hypotension had been made by his general practitioner and nifedipine discontinued. On further questioning he described increasing dysphagia for solid foods. His wife felt his speech had changed in character over a six-week period. He also complained of anorexia, persistent nausea, and a dry mouth during that time. Medical history included two myocardial infarctions, (the most recent 16 months previously) and a hiatus hernia diagnosed three years before. Prior to development of these symptoms he had been independent, a non-smoker and did not drink alcohol. Admission medications were aspirin $75 \mathrm{mg}$, lisinopril $5 \mathrm{mg}$, omeprazole $20 \mathrm{mg}$, isosorbide mononitrate LA $50 \mathrm{mg}$, all taken in the morning.

At the time of admission he was markedly hypotensive (supine blood pressure $60 / 30 \mathrm{mmHg}$ ) with a sinus bradycardia of 56 beats $/ \mathrm{min}$. His speech was low in volume and dysarthric. Neurological examination revealed weakness of neck flexion and tongue fasciculation but was otherwise normal. There were no other findings of note. In view of the hypotension, lisinopril and nitrates were stopped and supine blood pressure improved over the following 72 hours to stabilise at $90 / 60 \mathrm{mmHg}$.

The results of initial haematological and biochemical screens were normal, as was chest X-ray. An electrocardiogram (ECG) showed sinus arrhythmia and evidence of old infarction. Computed tomography (CT) of the brain was performed (figure 1).

Belfast City Hospital, Belfast, Northern Ireland B McGleenon IC Steele

Department of Geriatric Medicine, Whitla Medical Building, Queen's University of Belfast, 97 Lisburn Road, Belfast BT9 7BL, Northern Ireland AP Passmore

Accepted 21 March 1996

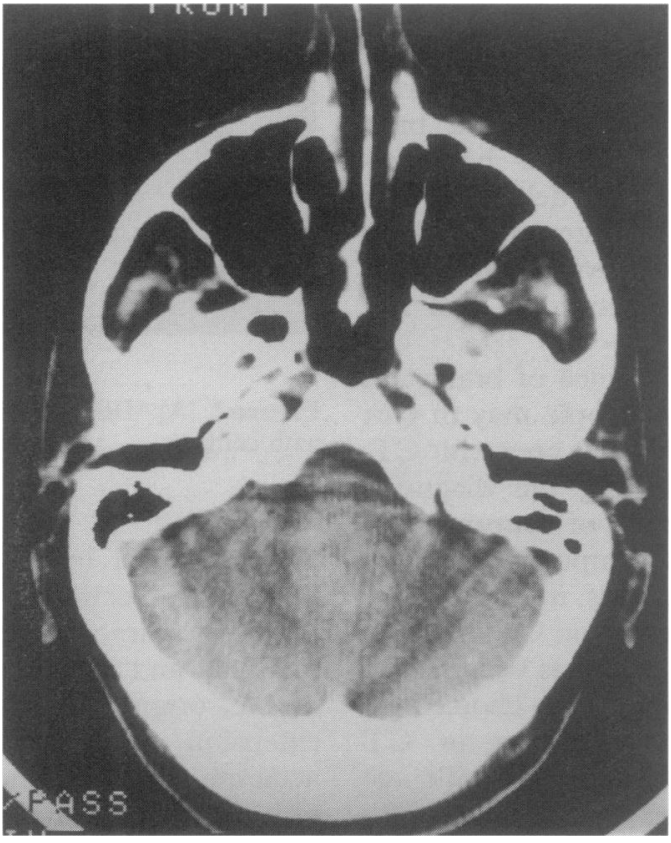

Figure 1 Brain CT scan

\section{Questions}

1 What does the CT scan show?

2 What is the most likely diagnosis?

3 Would you consider any other diagnoses?

4 What further investigations would you consider? 
Answers

QUESTION 1

The CT scan is normal.

QUESTION 2

Motor neuron disease.

QUESTION 3

Paraneoplastic syndrome, primary brainstem neoplasm, and metastic disease.

\section{QUESTION 4}

Nerve conduction studies, the results of which were normal; videofluoroscopy, which showed pooling of fluid in piriform fossa, no cough reflex and aspiration; magnetic resonance imaging (MRI), which revealed a $2-3 \mathrm{~cm}$ intra-axial mass in the inferior pontine/medullary area thought to be characteristic of primary brainstem glioma (figure 2).

\section{Discussion}

Brainstem glioma is an uncommon diagnosis with incidence rates of 1.7-6.0 per year in specialist neurological centres, ${ }^{1-3}$ mostly affecting patients under 18 years. ${ }^{4}$ It is said to be a rare diagnosis in elderly patients. Brainstem tumours represent a difficult diagnostic challenge. The onset is insidious with cranial nerve involvement, cerebellar and pyramidal symptoms. Common initial complaints include headache, mental changes, gait abnormalities, speech disturbance and dizziness. ${ }^{1}$ Uncharacteristic attacks with loss of tone and brief periods of unconsciousness have been reported. ${ }^{1}$ There may be a long delay between development of the first symptoms and diagnosis which is reported as varying between 14 days and 48 months $^{1}$ and between 1 and 180 months. ${ }^{3}$

The apparently low incidence of brainstem glioma reported in elderly people may in part be due to problems imaging this area with CT. Due to the difficulty making the diagnosis clinically, the appropriate use of neuroradiological investigations is very important. In this instance the correct diagnosis may not have been made if solely dependent on CT findings.

Since its introduction, MRI has become the neuroradiological procedure of choice for brainstem tumours. The difficulty in CT imaging of the brainstem increases with age which has been attributed to artefactual distortion by petrous bone. 4 ,5 This problem is accentuated in cases of brainstem glioma as they tend to be slightly hypodense or even isodense, show only slight enhancement after contrast and are recognised mainly by indirect signs. ${ }^{4}$ In a recent series of 16 cases of brainstem glioma, CT was normal in three

1 Strange P, Wohlert L. Primary brain stem tumours. Acta Neurochirurg 1982; 62: 219-32.

Nishio S, Takeshita I, Fujii K, Fukui M. Brainstem glioma: role of a biopsy. Br f Neurosurg 1991; 5: 265-73.

3 Guiney MJ, Smith JG, Hughes P, Yang C, Narayan K. Contemporary management of adult and pediatric brainstem gliomas. Int $\mathcal{Y}$ Radiat Oncol Biol Phys 1993; 25: 235 41 .

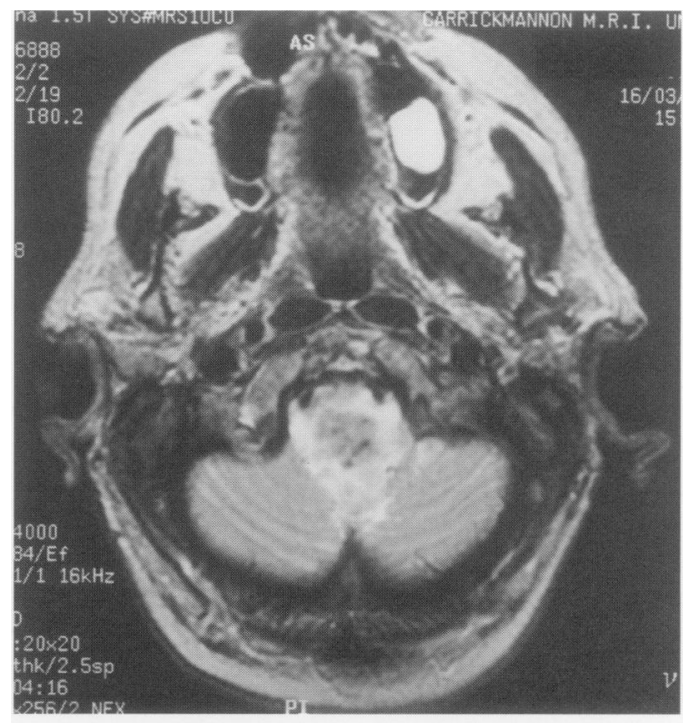

A

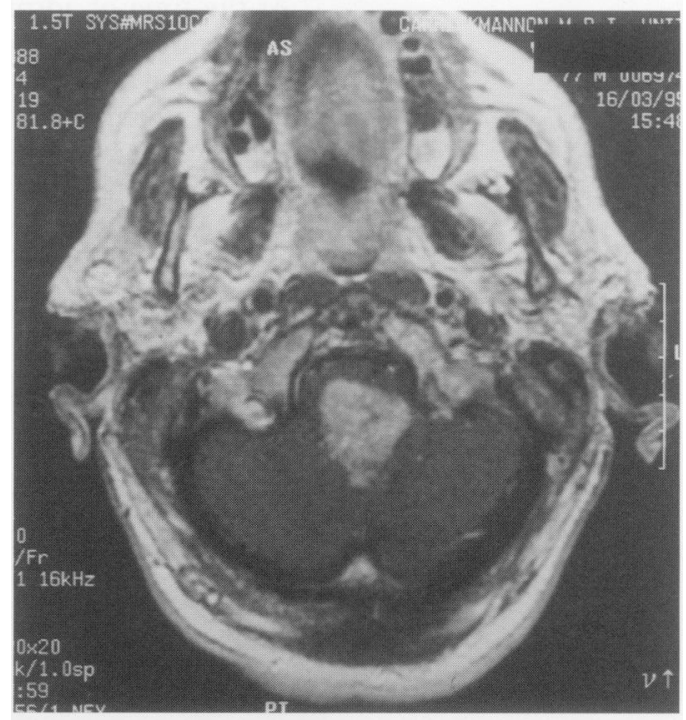

B

Figure 2 (A) MRI scan without contrast; (B) MRI scan with contrast

and equivocal in three, implying a possible failure of detection in $37.5 \%$ with CT alone. ${ }^{5}$ All of the tumours were clearly demonstrated on MRI, and this gave an accurate assessment of site, origin, dimensions, homogenicity and extension. MRI scan is recommended for accurate diagnosis and reporting of disease in older patients who present with suspected brainstem pathology.

\section{Final diagnosis}

\section{Brainstem glioma.}

Keywords: dysphagia, dysarthria, brainstem glioma

4 Colosimo C, Moschini M, Rollo M, Tartaglione T. Brainstem gliomas. Rays 1993; 18: 541-61.

5 Lee BCP, Kneeland JB, Walker RW, Posner JB, Cahill PT, Deck MDF. MR imaging of brainstem tumours. Am $\mathscr{f}$ Neuroradiol 1985; 6: 159-63. 